\title{
Transformações isométricas com manipulações em tela
}

\author{
Alexandre R. de Assis \\ Instituto de Educação Rangel Pestana-SEEDUC/RJ \\ Doutorando Programa de Pós-Graduação em Educação, Contextos Contemporâneos e Demandas \\ Populares - UFRRJ \\ profalexandreassis@hotmail.com
}

\section{Resumo}

As tarefas sugeridas nesta seção fazem parte de implementações realizadas com alunos do Ensino Médio, do Instituto de Educação Rangel Pestana. A proposta é composta por quatro tarefas utilizando as ferramentas de transformações isométricas disponibilizadas pelo GeoGebra para tablets. A primeira tarefa está direcionada para a utilização da ferramenta "reflexão"; a segunda, voltada para o processo de rotação; a terceira é orientada para a manipulação da ferramenta "translação"; e a quarta objetiva a elaboração de estratégias para o deslocamento de um polígono no plano utilizando as transformações isométricas. As tarefas podem ser utilizadas em smartphones e adaptadas para uso em outros softwares.

Palavras-Chave: Transformações isométricas. Tablet. GeoGebra. Ensino Médio.

\section{Isometric transformations with screen manipulations}

\begin{abstract}
The tasks suggested in this work are part of implementations carried out with High School students, from the Rangel Pestana Institute of Education. The proposal consists of four tasks using the isometric transformation tools provided by GeoGebra, mediated by tablets. The first task is directed to the use of the "reflection" tool; the second, oriented towards the rotation process; the third one is oriented to the manipulation of the tool "translation" and the fourth objective is the elaboration of strategies for the displacement of a polygon in the plane using the isometric transformations. Tasks can be used on smartphones and adapted for use in other software.
\end{abstract}

Keywords: Isometric Transformations. Tablet. GeoGebra. High School.

\section{Introdução}

No (re)pensar situações que promovam momentos de interações (aluno-aluno, aluno-professor, aluno-tablet) e propiciem aprendizagem deve ser considerada potencialidade dos artefatos mediadores (dispositivos com telas sensíveis ao toque, folha de tarefas, folha de ícones ${ }^{1}$, software,

\footnotetext{
${ }^{1}$ Veja em anexo. A folha de ícones consiste em tabelas com duas colunas: uma com os ícones e a outra, em branco. Cada tabela representava um ícone da barra de ferramenta e as ferramentas ocultas do GeoGebra. O objetivo é fazer com que os alunos explore cada ícone, analise as construções e registre suas observações tendo como base as construções resultantes.
} 
etc). A arquitetura do contexto formativo possibilita a produção de significados geométricos, como por exemplo, quando o aluno realiza a construção de um quadrilátero, a medida dos ângulos iguais não é o suficiente para garantir que se trata de um quadrado e, com isso, buscam-se meios para justificar e validar conjecturas elaboradas (ASSIS, 2016).

Temos visto que tarefas desenhadas tendo um dispositivo com telas sensíveis ao toque como artefato mediador, sem deixar de destacar o programa a ser utilizado, viabilizam interações e diferentes formas de representar (escrita, fala, pictórico, por exemplo). Dessa maneira, é possível observar avanços no processo de significação e no que se refere aos indícios de aprendizagem (ASSIS, 2016).

Dessa maneira, mesmo tendo estruturado o conjunto de tarefas para que fossem observadas performances dos alunos e as manipulações em telas sensíveis ao toque, a elaboração das tarefas teve, em sua maioria, atenção às transformações isométricas (simetria, rotação e translação), por abordarem assuntos pouco explorados no currículo (VELOSO, 2012) e por promoverem manipulações na tela que necessitam de observações sistemáticas de movimentos (BAIRRAL et al., 2015b).

\section{Um pouco sobre a implementação e as tarefas}

O conjunto de tarefas foi elaborado para ser implementado em dois tempos de aula, o equivalente a uma hora e quarenta minutos, com alunos do $1^{\circ}$ ano do Ensino Médio. A proposta não objetiva a formatação e inalterabilidade do corpo da tarefa, mas deseja-se que seja algo inspirador para o docente e que possa adaptar à sua realidade. As manipulações touchscreen podem estar relacionadas à "característica do software ou à natureza da tarefa" (BAIRRAL et al., 2015a, p. 96).

Foi importante definir o tipo de dispositivo - tablet, neste caso - e o tipo de software GeoGebra touch ${ }^{2}$-, pois as especificidades de cada artefato podem interferir no desenho da tarefa, dificultando a construção e, dessa maneira, desviando do objetivo que são as transformações isométricas e possíveis combinações.

A proposta conta com três tarefas de cunho mais exploratório, cada uma abordando uma ferramenta específica - reflexão, translação e rotação -, nas quais o discente pode realizar construções e analisar especificidade(s) e potencialidade(s) de cada ferramenta. Além das três atividades, proponho uma quarta tarefa, que propicia a elaboração de alguma(s) estratégia(s) em que seja(m) utilizada(s) a(s) ferramenta(s) reflexão, rotação e/ou translação.

As implementações podem ser realizadas em dupla ou individualmente, utilizando tablets ou smartphones. Em nenhuma dessas atividades os alunos tinham o conhecimento prévio sobre

\footnotetext{
${ }^{2}$ Versão 4.3.
} 
assuntos relacionados às transformações geométricas de maneira sistematizada. Durante uma das interações que emergiu em uma das atividades, alunos apresentaram a reflexão associada à ideia do espelho (ASSIS, 2016). Nas tarefas, sem dedicar uma preocupação em nomear a ferramenta, o aluno pode realizar uma construção orientado pelas indicações pelos ícones. Dessa maneira, tem a oportunidade de manipular de maneira mais livre e observar a resposta dada pelo dispositivo ao seu manuseio e realizar suas inferências.

Realizada em dupla ou individual, a implementação pode ser dividida em dois momentos. O primeiro momento é composto pelas três primeiras tarefas, que podem ser configuradas como simples utilizações de uma ferramenta específica, porém servirão para o entendimento e inferências acerca do comportamento de cada uma das transformações abordadas que auxiliam no desenvolvimento da tarefa do segundo momento, a Tarefa 04 , segundo sinalizo no quadro 1.

Quadro 01 - Divisão das tarefas

\begin{tabular}{|c|c|c|l|}
\hline Momento & Tarefas & Tempo estimado & \multicolumn{1}{c|}{ Dimensão cognitiva } \\
\hline $1^{\circ}$ & $01,02,03$ & $40 \mathrm{~min}$ & $\begin{array}{l}\text { Realização de construções com procedimentos auxiliados } \\
\text { pelas sugestões de ícones, objetivando a elaboração de } \\
\text { novos significados a partir de observações realizadas, } \\
\text { viabilizando o estabelecimento de novas conexões, tendo } \\
\text { como base transformação abordada na referida tarefa. }\end{array}$ \\
\hline $2^{\circ}$ & 04 & 60 min & $\begin{array}{l}\text { Estabelecer relações com as Tarefas 01, 02 e/ou 03, } \\
\text { elaborando conjecturas, interpretando e julgando-as, } \\
\text { possibilitando (re)significações e a elaboração de uma } \\
\text { estratégia para resolução do problema. }\end{array}$ \\
\hline
\end{tabular}

Fonte: Elaborado pelo autor.

\section{As Tarefas sugeridas}

Nesta seção apresento as tarefas propostas (Quadros 2, 3 e 4).

Quadro 2 - Tarefa "Utilizando a ferramenta reflexão"

\begin{tabular}{l}
\hline Tarefa \\
\hline 01 \\
\hline Utilizando a ferramenta \\
Construa um triângulo qualquer com a ferramenta \\
Selecione. \\
Vamos observar o que acontece quando utilizamos a ferramenta \\
Com o ícone selecionado, toque sobre a região do triângulo e depois sobre a reta. \\
(a) O que aconteceu? \\
(b) Movimente livremente os vértices do triângulo ABC. O que você percebe de interessante?
\end{tabular}




\begin{tabular}{|c|c|}
\hline \multicolumn{2}{|c|}{$\begin{array}{l}\text { Construa o segmento de reta } \overline{\mathrm{AA}^{\prime}} \text { e depois marque o ponto de intersecção }(\chi) \text { do segmento } \overline{\mathrm{AA}^{\prime}} \text { com } \\
\text { a reta } \overline{\mathrm{DE}} \text {. } \\
\text { (c) O que podemos afirmar em relação às distâncias } \overline{\mathrm{AF}} \text { e } \overline{\mathrm{FA}^{\prime}} \text { ? Justifique sua resposta. } \\
\text { (d) Salve sua construção com o nome da dupla. }\end{array}$} \\
\hline Tela captu & Pode ajudar nas interações... \\
\hline 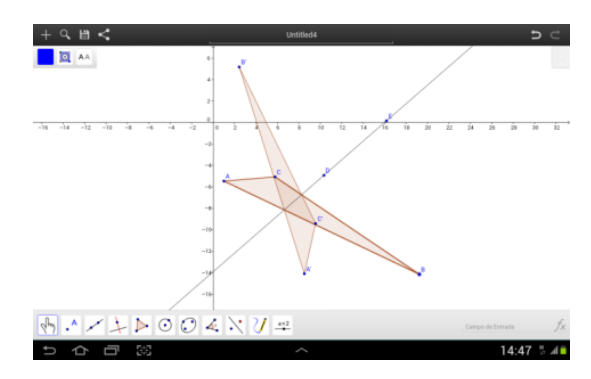 & $\begin{array}{l}\text { - Verificar o comportamento das construções ao manipular } \\
\text { - Am de seus elementos. } \\
\text { visto como uma reta divisória do plano. } \\
\text { - Ressaltar a conservação da medida de área e perímetro. } \\
\text { - Destacar a troca de orientação. } \\
\text { - Mediatriz de um segmento. } \\
\text { - Analisar e relacionar manipulações realizadas na tela do } \\
\text { dispositivo com o resultado dado }\end{array}$ \\
\hline
\end{tabular}

Fonte: Elaborado pelo autor.

Quadro 3 - Tarefa "utilizando a ferramenta rotação"

\begin{tabular}{|c|c|c|}
\hline Tarefa & Utilizando a ferramenta $\dot{\rho}$. \\
\hline
\end{tabular}

- Construa um quadrado utilizando a ferramenta "polígono regular".

- Selecione a ferramenta $\$$. Com o ícone selecionado, toque no quadrado e em um de seus vértices. Escolha um ângulo e um sentido (horário ou anti-horário).

(a) Descreva para seu colega o que acontece.

(b) Movimente livremente a figura original. O que você observa de interessante?

Salve sua construção.

\begin{tabular}{|l|l|}
\hline Tela capturada & \multicolumn{1}{c|}{ Pode ajudar nas interações... } \\
\hline & $\begin{array}{l}\text { Destaque para o centro de rotação. } \\
\text { Observar o sentido da rotação, efetuando giro no sentido } \\
\text { horário e horário. } \\
\text { Analisar o resultado de uma composição de rotações. } \\
\text { Verificar se é possível ter uma rotação como resultado de } \\
\text { uma composição de reflexões. }\end{array}$ \\
& \\
\hline
\end{tabular}

Fonte: Elaborado pelo autor.

Quadro 4 - Tarefa "Utilizando a ferramenta translação"

\begin{tabular}{|c|c|}
\hline $\begin{array}{c}\text { Tarefa } \\
03\end{array}$ & Utilizando a ferramenta \\
\hline $\begin{array}{ll}\text { - } & \text { Con } \\
\text { - } & \text { Sele } \\
\text { - Toq }\end{array}$ & $\begin{array}{l}\text { trua um quadrilátero qualquer. } \\
\text { eione a ferramenta quadrilátero construído e, em seguida, em dois pontos distintos na área de trabalho. } \\
\text { a) Observe o que ocorreu e descreva para seu colega. }\end{array}$ \\
\hline
\end{tabular}




\begin{tabular}{|c|c|}
\hline \multicolumn{2}{|c|}{ (b) Movimente livremente a figura original, selecionando toda figura ou um de seus vértices. } \\
Registre suas observações. \\
\hline \multicolumn{2}{|c|}{ Tela capturada } \\
\hline \begin{tabular}{l} 
Pode ajudar nas interações... \\
\hline
\end{tabular} & $\begin{array}{l}\text { Com a utilização da ferramenta translação, o discente } \\
\text { movimenta o vetor e verifica o deslocamento. } \\
\text { Associar ideia de deslocamento e verificando a troca ou } \\
\text { não de orientação } \\
\text { Verificar se é possível obter uma translação com uma a } \\
\text { realização de duas reflexões } \\
\text { Observar o comportamento da figura transladada ao } \\
\text { realizarmos movimentos giratórios no vetor variando o } \\
\text { seu comprimento. } \\
\text { Analisar se é possível ter uma translação como resultado } \\
\text { de uma composição de translações }\end{array}$ \\
\hline
\end{tabular}

Fonte: Elaborado pelo autor.

Quadro 5 - Tarefa "Deslocando o polígono"

\begin{tabular}{|l|l|l|}
\hline Tarefa & Deslocando o polígono \\
\hline - & Abra o arquivo "Deslocando o polígono", disponível em https://www.geogebra.org/m/KMKGRs6w \\
& Teremos a seguinte construção: \\
Utilize apenas as ferramentas \\
Que ferramenta(s) foi(ram) utilizada(s) para deslocar a figura ABCDE na figura A"B”C'D"E”? \\
Descreva.
\end{tabular}

Fonte: Elaborado pelo autor.

Com este conjunto de tarefas, podemos possibilitar ao docente vivenciar situações que estimulem o desenvolvimento de processos de internalização e que viabilizam a promoção de aprendizagem com o despertar de processos internos de desenvolvimento decorrente de interações (OLIVEIRA et al., 1992). Nesse sentido, ir além de procedimentos engessados e formatados, com uma mediação cognitiva, objetivando o desenvolvimento do outro em diferentes contextos e com ferramentas diferenciadas, é não restringir a liberdade de atuar. As ações formativas planejadas influenciam no processo de construção do conhecimento científico.

Com o desenrolar da quarta atividade identificam-se o refinamento da escrita e seleção de ferramentas que resultaram na construção descrita, além de destacar a preocupação na indicação de 
sequências das transformações utilizadas. A Figura 1 ilustra o recorte do registo realizado por um aluno em uma das implementações, no qual utiliza a própria figura e ícones do programa na explanação da estratégia elaborada.

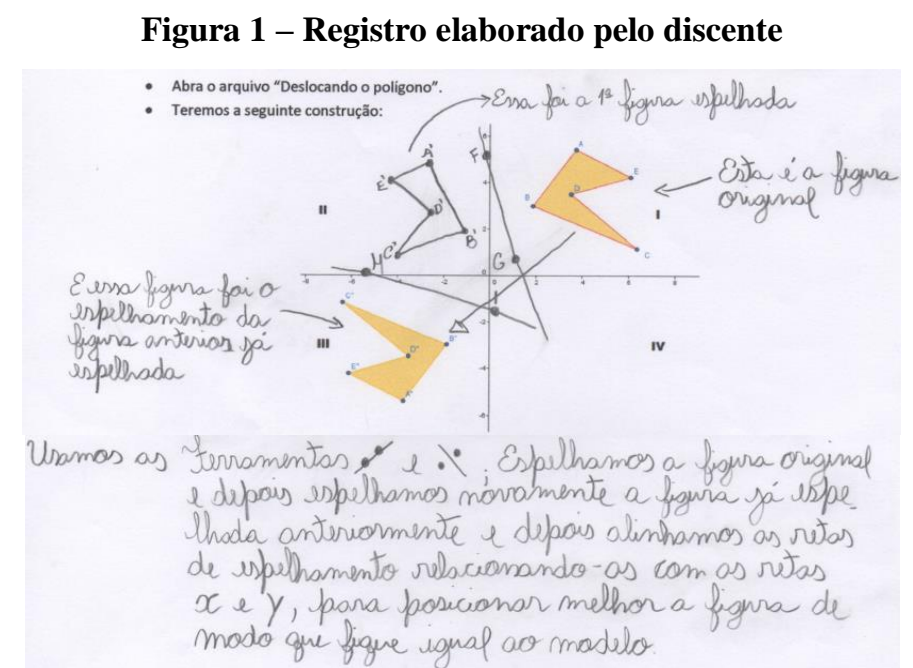

Fonte: Material de pesquisa do autor.

O registro apresentado foi fruto das interações e da troca com o outro, com uma valorização de representações pictóricas, tendo como elemento principal momentos de exploração e elaboração de conjecturas, que propiciaram situações em que o discurso não está dissociado das manipulações que compõem o processo de negociação e convencimento.

\section{Algumas considerações}

As atividades proporcionam a arquitetura de um ambiente formativo que viabiliza a construção de significados. Dessa maneira, estimular a reflexão e novas estratégias para a resolução de um mesmo problema, associada ao conhecimento de distintas ferramentas, instiga o discente sobre ações realizadas, possibilitando interações com questionamentos com os quais o discente se sinta à vontade para oralizar procedimentos adotados.

Manipulações touch associadas ao discurso, a escrita e representações pictóricas podem fornecer indícios de aprendizagem e construção de conhecimento. É importante oportunizar momentos de registro escrito, mesmo que não seja da maneira sistematizada com domínio de termos matemáticos. Destacamos, ainda, que, no desenvolvimento das atividades e maior familiaridade com o GeoGebra touch, foi possível identificar que alunos realizaram refinamento nas construções.

Cabe destacar que as atividades são adaptáveis, pois podem ser reelaboradas pensando em outros softwares de geometria dinâmica, como por exemplo o FreeGeo, o Sketchomentry e o Geometric Constructer. Pesquisas (BAIRRAL et al., 2015b, 2017) sinalizam resultados que 
evidenciam estratégias não convencionais dos alunos na solução de tarefas abordando alguma isometria.

Espero que essa contribuição possa servir de inspiração aos colegas, pois entendo que as tarefas propostas são adaptáveis (ao dispositivo, programa, contexto, etc.), cujas potencialidades não se findam em um breve espaço de tempo, pois com manipulações em tela é possível realizar transformações.

\section{Referências}

ASSIS, A. R. de. Alunos do Ensino Médio trabalhando no GeoGebra e no Construtor Geométrico: Mãos e rotAções em touchscreen. 2015. 158p. Dissertação (Mestrado em Educação). Instituto de Educação / Instituto Multidisciplinar, PPGEduc, Universidade Federal Rural do Rio de Janeiro, Nova Iguaçu, RJ. 2016. Disponível em: <http://www.gepeticem.ufrrj.br/portal/wpcontent/uploads/2017/04/Disserta\%C3\%A7\%C3\%A3o_Alexandre-Rodrigues-de-Assis.pdf >

BAIRRAL, M., ASSIS, A., SILVA, B. C. Mãos em ação em dispositivos touchscreen na educação matemática. Seropédica, RJ: EDUR, 2015a. 115p. (Série InovaCom TIc, v.7). Versão eBook disponível em: <https://itunes.apple.com/br/book/maos-em-acao-emdispositivos/id1132206515? $\mathrm{mt}=11>$

BAIRRAL, M. A., ARZARELLO, F., ASSIS, A. High School students rotating shapes in GeoGebra with touchscreen. Quaderni di Ricerca in Didattica: Matematica 25 (suplemento 2) Proceedings CIEAEM 67, p.103-108, 2015b.

BAIRRAL, M., ARZARELLO, F., ASSIS, A. Domains of manipulation in touchscreen devices and some didactic, cognitive and epistemological implications for improving geometric thinking. In G. Aldon, F. Hitt, L. Bazzini, \& U. Gellert (Eds.), Mathematics and technology: a CIEAEM source book , p. 113-142. Springer, 2017.

OLIVEIRA, M. K. de. Vygotsky e o processo de formação de conceitos. In: TAILLE, Y. de la, OLIVEIRA, M. K., DANTAS, H. Piaget, Vygotsky, Wallon: Teorias psicogenéticas em discussão. 23. ed. São Paulo: Summus editora, 1992. 117p.

VELOSO, E. Simetria e transformações geométricas. Lisboa: APM, 2012.

\section{Anexo - Folha de ícones}

Tela inicial
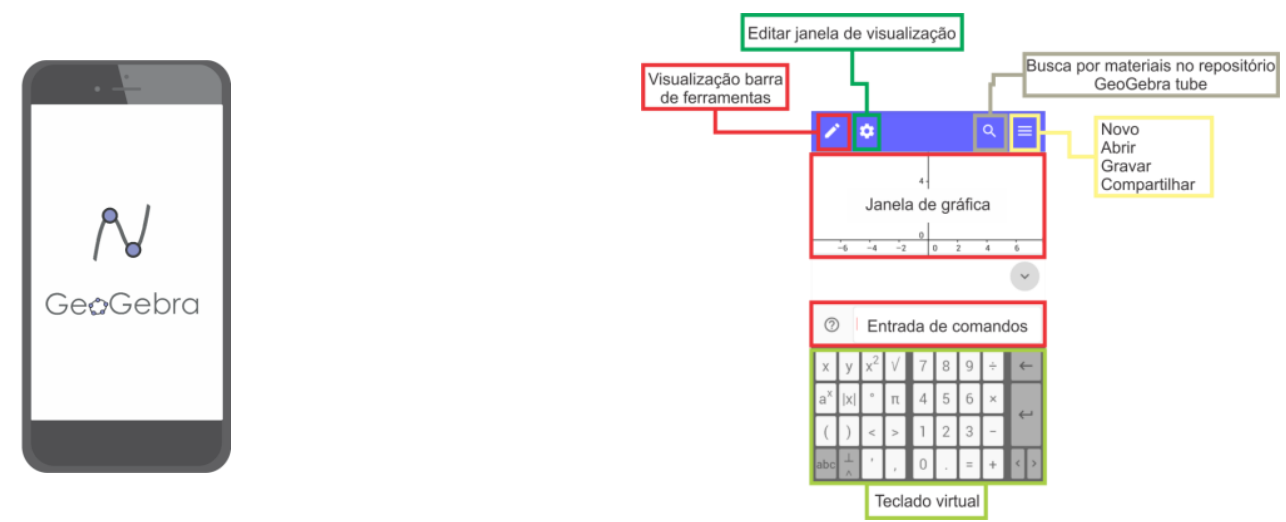
Barra de ferramentas

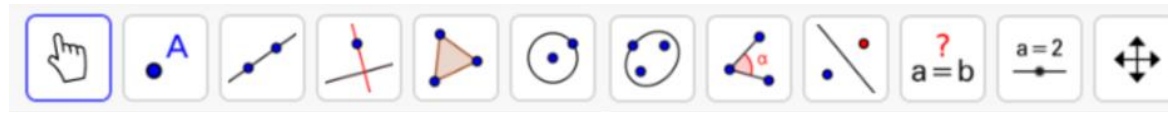

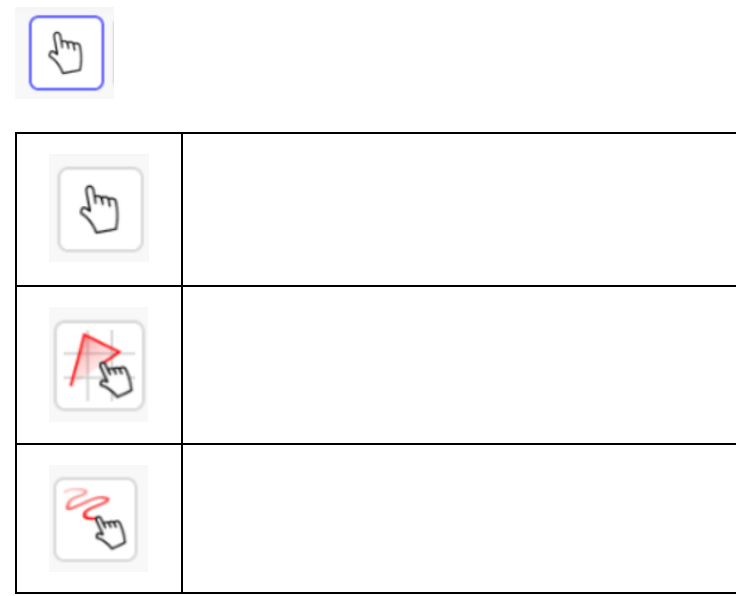

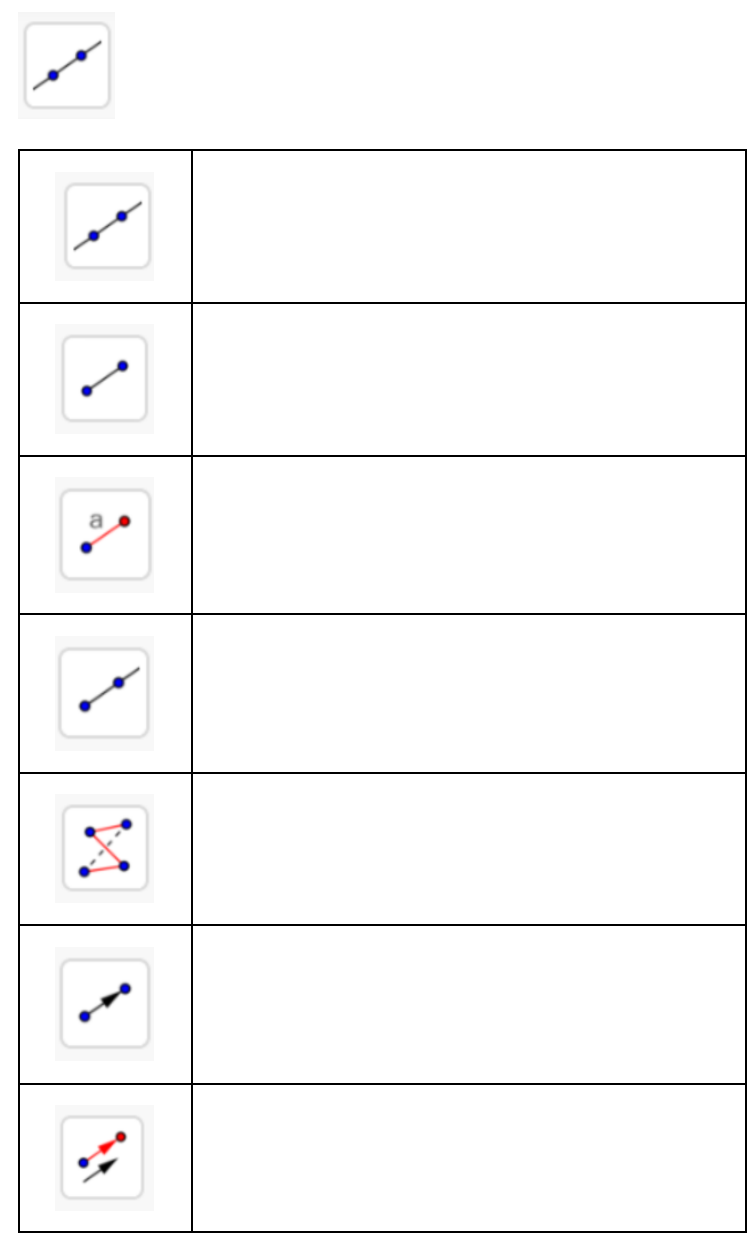

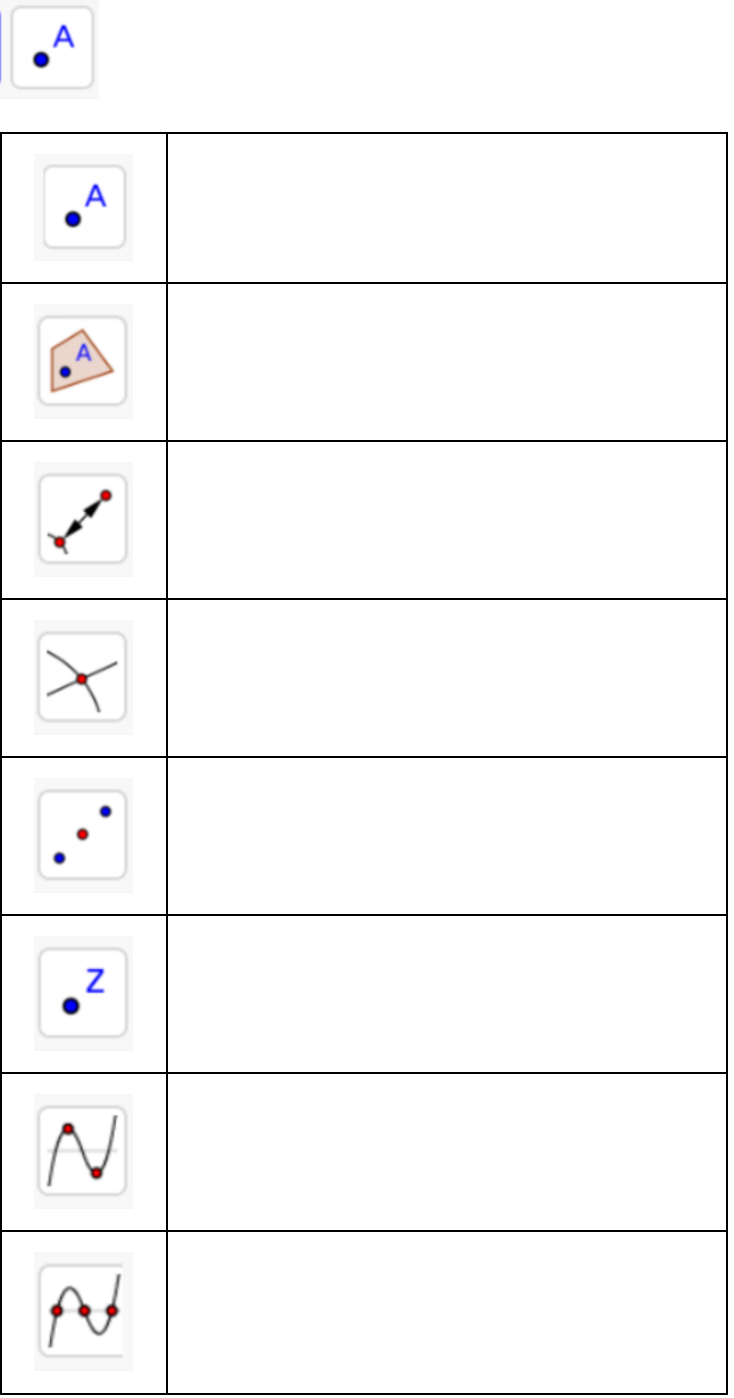

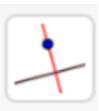

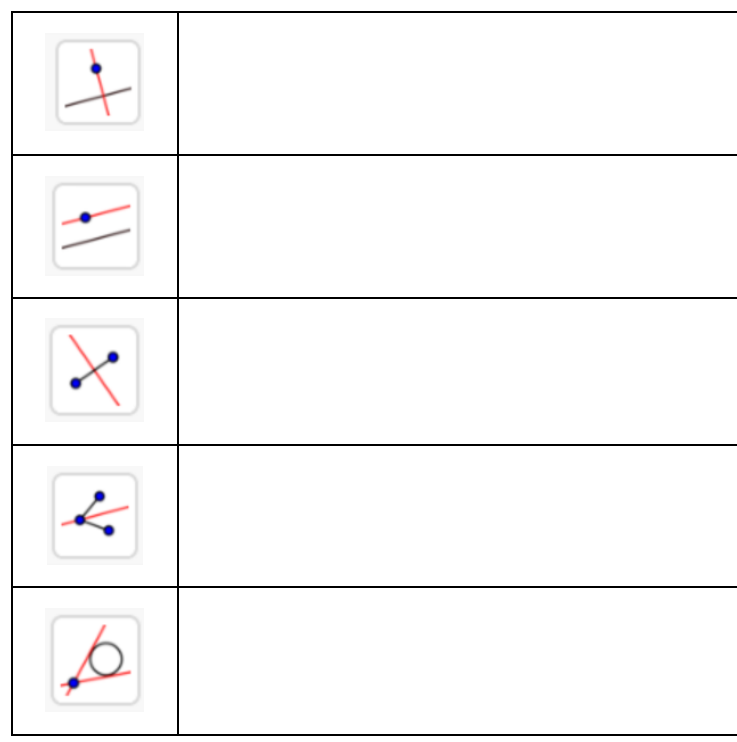




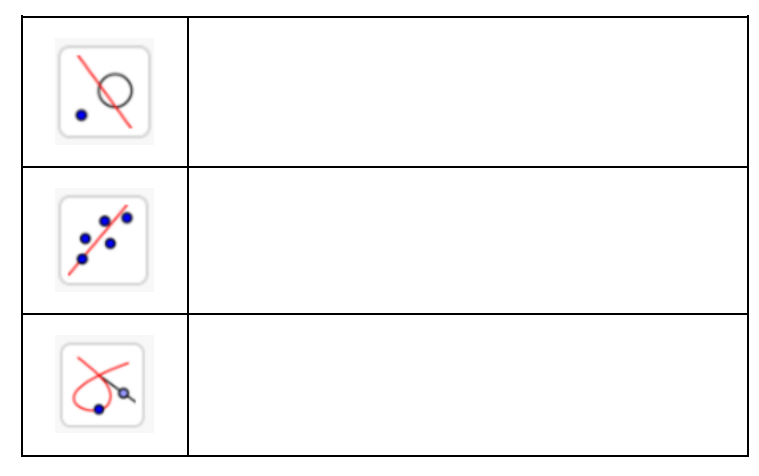

$>$

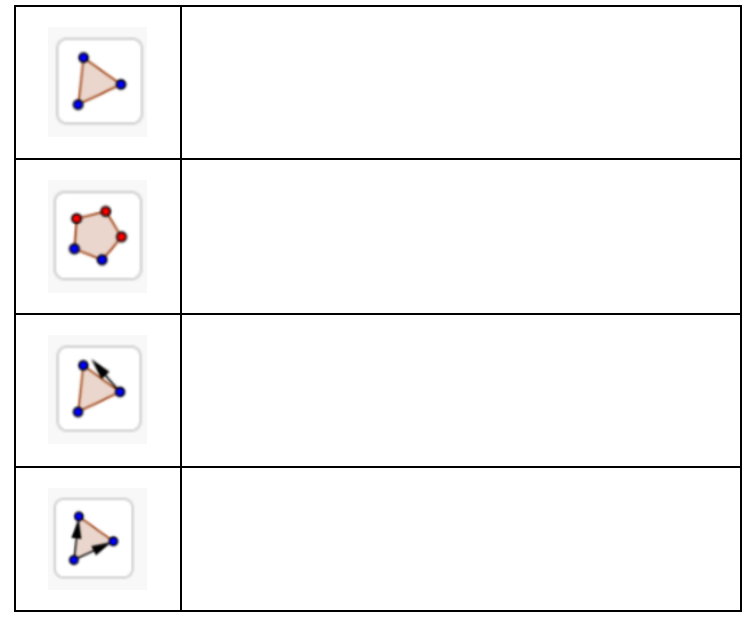

$\odot$

\begin{tabular}{|l|l|}
\hline$\odot$ & \\
\hline$\odot$ & \\
\hline$\odot$ & \\
\hline & \\
\hline$\odot$ & \\
\hline
\end{tabular}

\begin{tabular}{|l|l|}
\hline$\therefore$ & \\
\hline$\partial$ & \\
\hline$\Delta$ & \\
\hline$\gamma$ & \\
\hline
\end{tabular}

$\odot$

\begin{tabular}{|l|l|}
\hline$\odot$ & \\
\hline$\therefore$ & \\
\hline & \\
\hline & \\
\hline
\end{tabular}

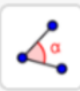

\begin{tabular}{|c|c|}
\hline \multicolumn{2}{|l|}{ 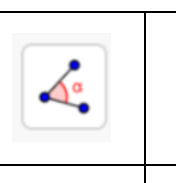 } \\
\hline 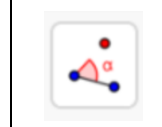 & \\
\hline $\mathrm{cm} /$ & \\
\hline 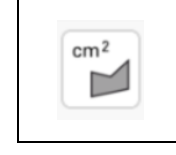 & \\
\hline
\end{tabular}



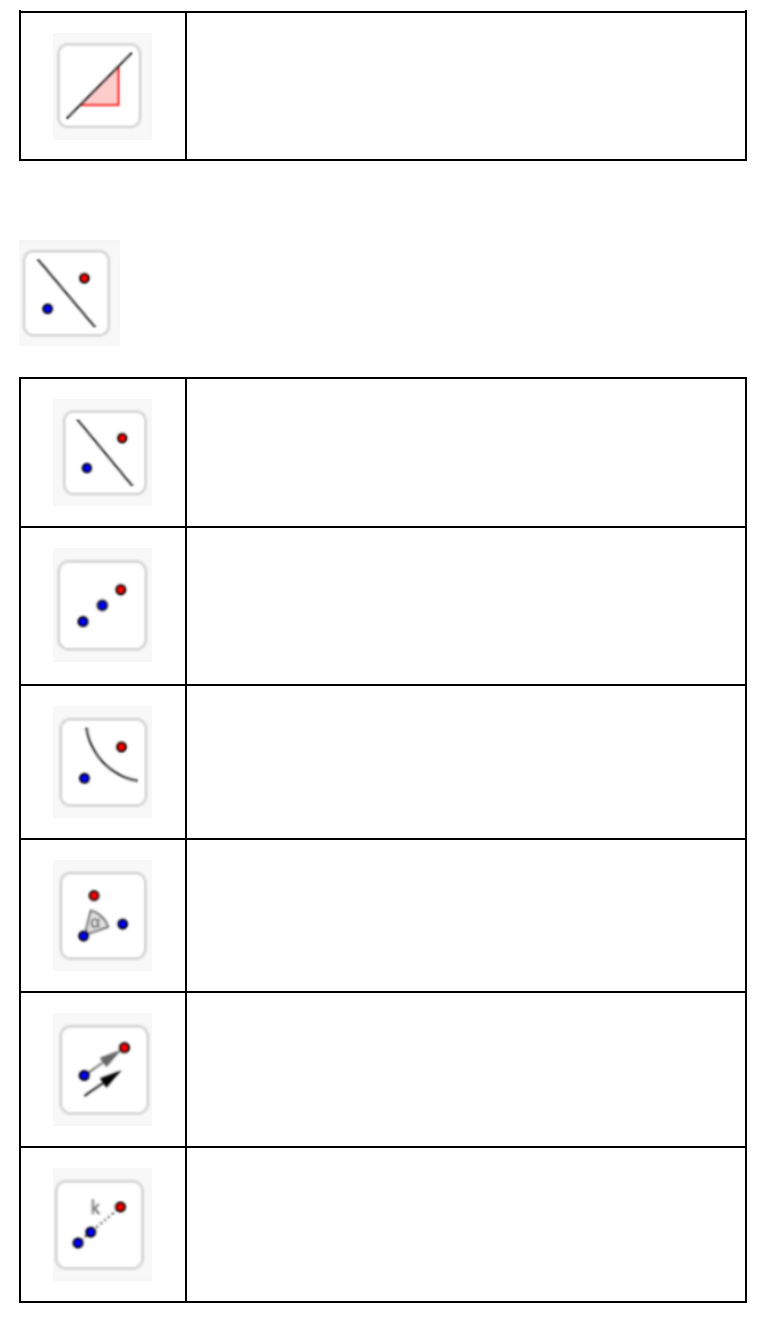

$a \stackrel{?}{=} b$
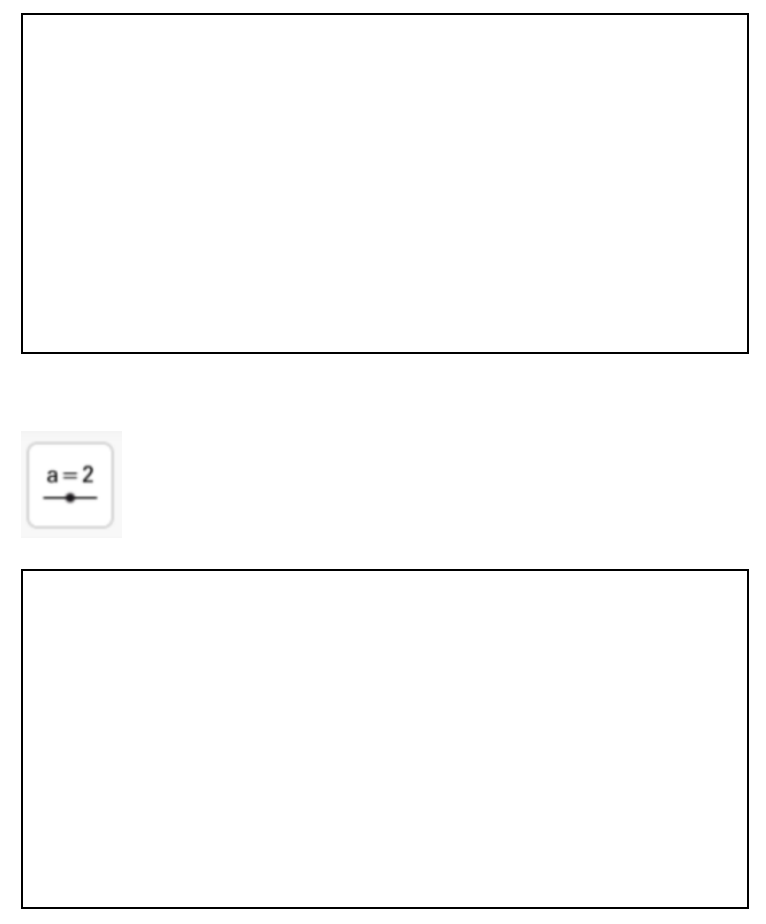

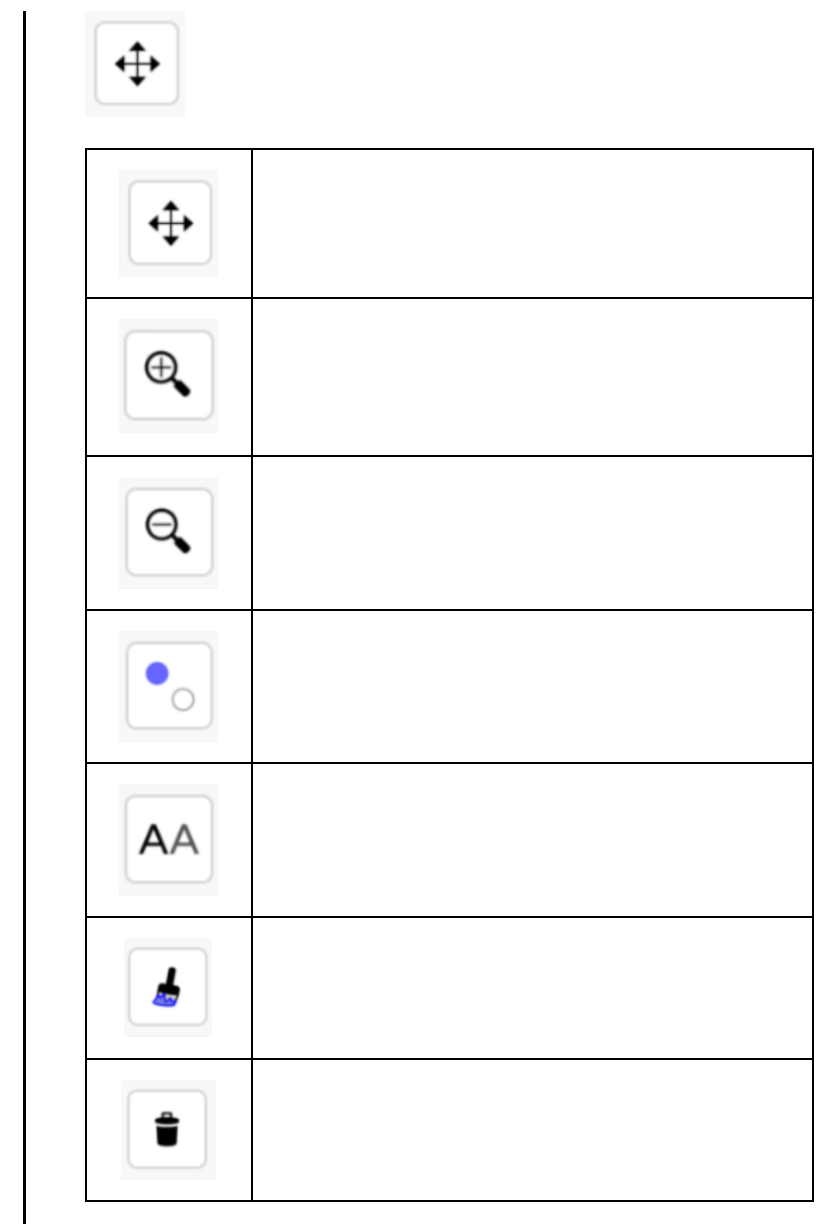

195 
Telas Auxiliares

;

$\leftarrow \quad$ Janela de Visual... त $\bigotimes_{0}$

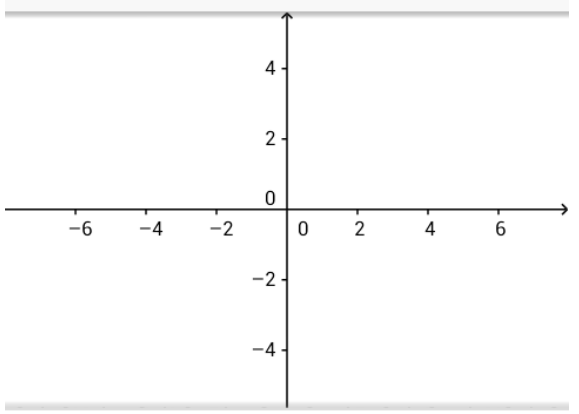

十井㻌楼

Legendas

Desativar

Distância

Modo Automático

Arredondamento

2 Casas Decimais

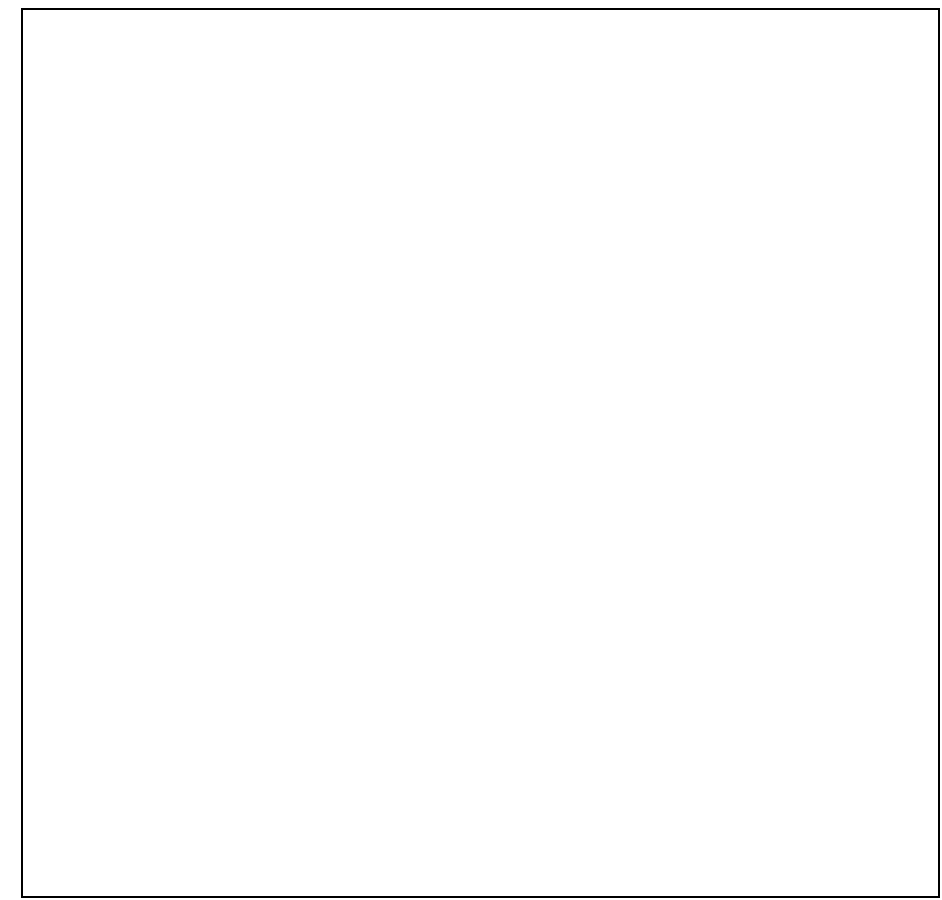

$+\quad$ Novo

Q Abrir

G Gravar

Compartilhar

? Ajuda

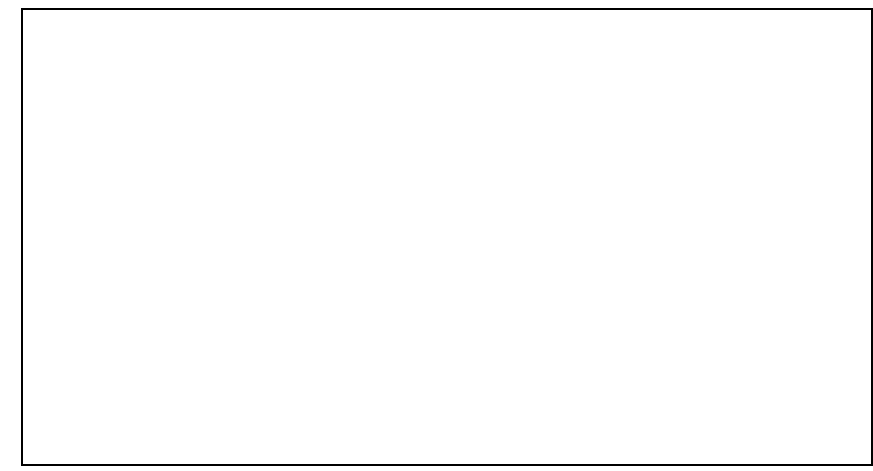


$\leftarrow \quad$ Procurar em Todos os Com $\quad \times$

Funções Matemáticas

Todos os Comandos

$3 D$

Cônicas

Diagramas

Estatística

Funções e Cálculo

GeoGebra

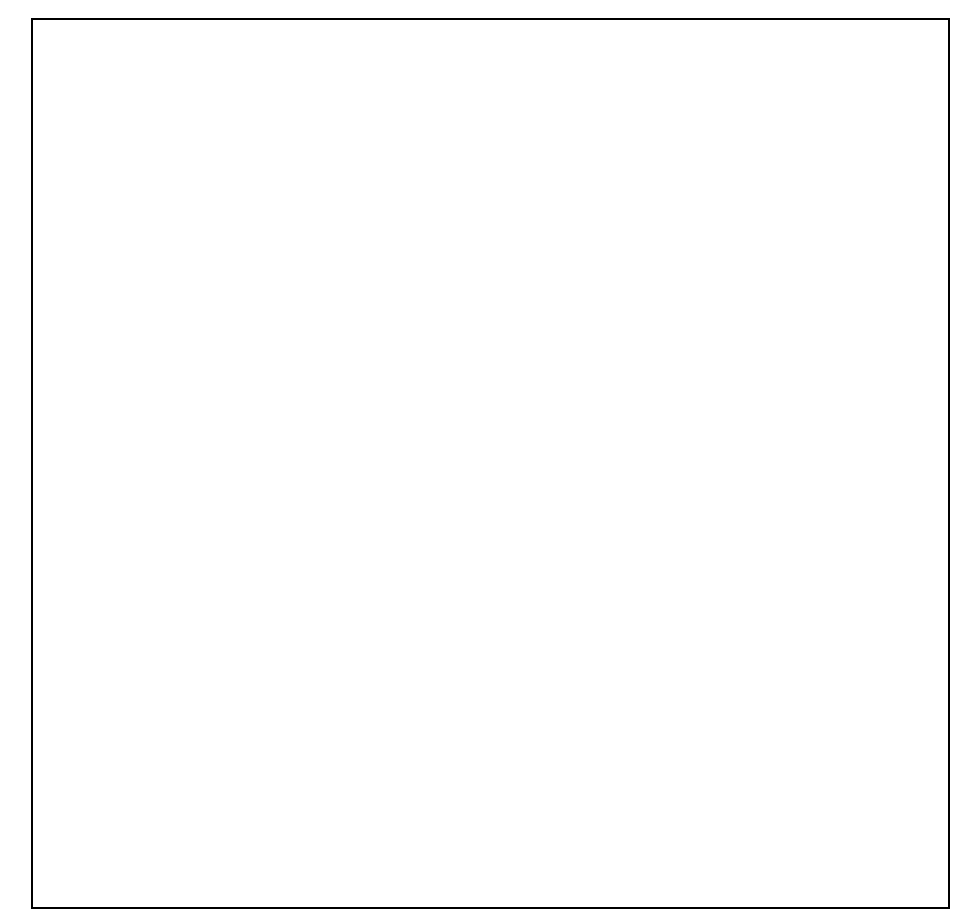

Teclado Virtual
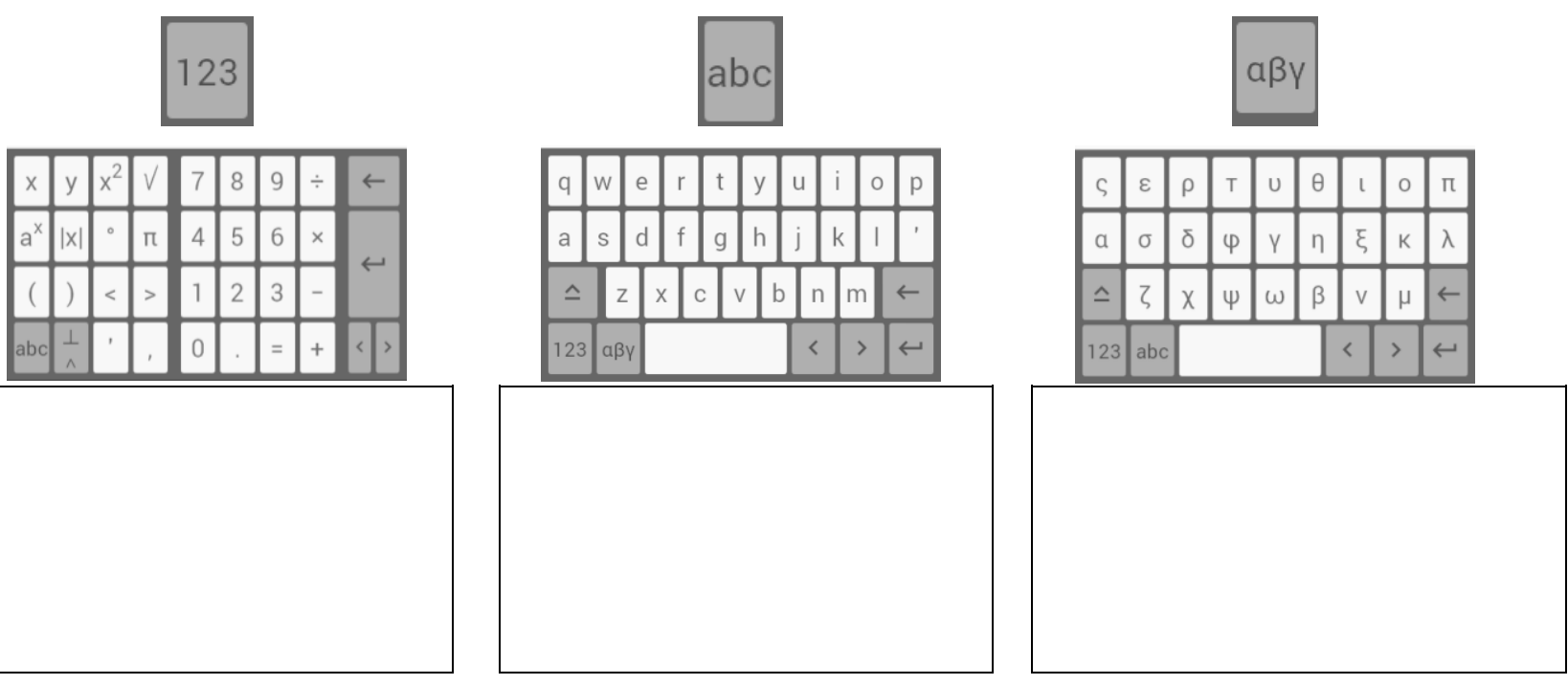

Submetido em janeiro de 2017

Aprovado em março de 2017 